Assessing enterprise wiki success from the perspective of end-users: an empirical approach

Zeeshan Ahmed Bhatti

Faculty of Economics \& Administration, King AbdulAziz University, Jeddah, 21589, Saudi Arabia

Serge Baile

Department of Management Information Systems, Universite Toulouse 1 Capitole, Toulouse, France

Hina Mahboob Yasin

IAE Graduate School of Management, Aix en Provence, France 


\title{
Assessing Enterprise Wikis' Success from the Perspective of End-Users: An Empirical Approach
}

\begin{abstract}
:
The success of wikis on Internet has led the organizations to introduce wikis within corporate settings for multiple purpose. However, despite the popularity of wikis in public and subsequently in the corporate environment, an empirical investigation of their benefits within organizations is still lacking. This study performs an empirical investigation with 177 corporate wiki end-users to evaluate their performance after wiki use. Enterprise wiki end-user performance is evaluated by measuring user's efficiency, effectiveness and capacity development. PROCESS macro in SPSS is used to empirically test specific indirect effects via mediation. The findings suggest that the collaboration quality, information quality, and system quality of enterprise wikis help its users in increased efficiency, effectiveness, and their capacity development.
\end{abstract}

Keywords: Enterprise wikis, Collaboration, Employee productivity, Individual performance, IS evaluation, 


\section{Introduction}

Wikis have emerged with the advent of Web 2.0 that has brought a revolution in the way users now access online information and can be a part of online knowledge creation. Different Web 2.0 technologies have attracted the attention of firms, particularly of large multinational organizations. The closest of Web 2.0 tools to traditional IS are wikis that almost perfectly relate to the creation of knowledge spiral. The basic phenomenon behind this functionality is the underlying collaboration that wikis offer for knowledge sharing. Wikis exploit the basic nature of human beings to be collaborative. The basic task of wikis in a corporate environment is to offer collaboration to efficiently and effectively manage current and future projects of a firm. They support acquisition of knowledge, collaborative work, and communication among members of a firm (Vreede et al. 2016).

Although wikis are more popular on the Internet (e.g. Wikipedia), they have made their way in organizational communication (Wagner and Schroeder 2010). Wikipedia is not the only successful Internet wiki, there are numerous other wiki-based websites that successfully allow their users to collaboratively create and share documents such as Vienna history wiki (Bensing 2015) and crowd sourced law reforms in Finland (Aitamurto and Landemore 2015). The success of wikis on Internet has led the organizations to introduce wikis within corporate settings for multiple purposes and the number is growing (Kayhan 2015). A few researchers argued that this shift of public wikis to enterprise wikis might not be successful due to command and control culture of enterprises (Arazy et al. 2009). Albeit, a number of studies have stressed on the increase in enterprise wiki adoption and implementation (Grace 2009; Razmerita and Kirchner 2011; Bhatti, Baile, and Yasin 2011). In response, wikis are deployed for multipurpose use such as customer resource management (Ortega and Barahona 2007), software development (Trkman and Trkman 2009; Milovanović et al. 2012), group projects (Morgan et al. 2013), new product development (Reid et al. 2016), and in the educational setting (Fominykh et al. 2016; Heidrich et al. 2015; Matschke, Moskaliuk, and Kimmerle 2013) but there is a need to evaluate their role in such collaborative tasks. However, the question do corporate wikis benefit the endusers' performance is still underexplored. Hence, this study attempts this research question by focusing on collaboration, information, and system features of corporate wikis to test their effect on individual users' performance in organizations.

Since the advent of wikis, they have been the nucleus of a substantial amount of discussion by academic researchers and practitioners. These research discussions often focus on the benefits that wikis provide in a corporate environment for various purposes. The tasks, for which corporate wikis are thought to be used, vary a great deal, but mostly the corporate usage rationale has been for collaborative content building and documentation. The collaboration provided by wikis may help their users to perform better. The collaboration mechanism on which the wikis are built allows their users to readily and accurately get needed information. However, an empirical investigation of wiki-end users' perceptions is still missing in the enterprise wiki research as to whether wikis can help their users enhance their work place performance.

Building on this need, this study examines the effect of enterprise wiki quality on end-users' performance mediated by wiki use and wiki user satisfaction and aims to contribute to the existing IS literature concerning IS success evaluation. DeLone \& McLean (D\&M) Model (2003) has been used widely to measure the success of various organizational system, however, the existing measures in D\&M do not cater for the collaborative feature provided by wiki systems. Therefore, we draw on D\&M (2003) IS success model and extend it in the context of enterprise wikis in the following ways. First, this study evaluates the wiki systems from three perspectives, namely collaboration quality, information quality, and system quality. Even 
though, there has been some research on wiki evaluation but the collaborative feature of the system has not been taken into consideration categorically. Secondly, in contrast to traditional IS, wiki use is different in nature in the sense that some users are actively participating in building content or documents while the others are just passive readers. This research takes into account this dynamic nature of wiki use and classify wiki use as active or passive use. Lastly, building on D\&M model which proposes IS success factors have net impacts on individual or organizational level, this paper considers multiple individual performance indicators to measure wikis success.

\section{Theoretical Foundation}

\subsection{IS Success Measurement and Enterprise Wikis}

The contemporary business success in terms of profitability and gaining competitive advantage now depends on Information Technology (IT) and especially the capacity of MIS functions to implement and manage projects. Thus, a number of different theoretical models have been proposed in literature to measure different ISs' success. DeLone \& McLean (1992) presented a taxonomy to better understand the different dimensions of IS success. They argued that the model was aimed to make the research on IS success more logical and provided a well explained outcome measure that can be used in the evaluation of IS. D\&M IS success model was proposed in continuation of the research conducted as a part of the evaluation of IS and was aimed at summarizing the IS evaluation research. The analysis of past research allowed them to see large disparity of measures as they stated "...in searching for an IS success measure, rather than finding one, there are nearly as many measures as there are studies" (DeLone and McLean 1992). Therefore, they classified the existing studies into six major interdependent multidimensional categories, which have been widely used to evaluate IS success.

The first level of D\&M IS success model consists of perceived IS evaluation constituting perceived system and information quality of an IS. System quality (SQ) refers to the production and the processing of data. It generally measures technical performance by analysis of factors such as response time, structure of the database, ease of system use, and system reliability. Information quality (IQ) measures the quality of results of the IS since it refers to the output of the system. IQ perception can be regarding information's relevance, accessibility, presentation, and users' adaptability needs. Ten years later DeLone \& McLean (2003) presented an updated model reviewed in the light of main criticisms (Rai, Lang, and Welker 2002; Seddon 1997; Kiew and Seddon 1994) to their first model. This model was presented primarily to measure the success of e-commerce websites. A major modification to the original D\&M model was the addition of 'service quality' construct along with SQ and IQ. This construct was added to address the changing nature of IS which required an evaluation of the services provided through an IS. A second modification to D\&M IS success model was to introduce 'net benefits' rather than 'individual impact' and 'organizational impact' as the dependent variables, thus implying that IS can affect different levels of use. They further argue that service quality dimension is more important in an e-commerce environment since on websites the users are customers rather than employees, and therefore, poor customer support can result into sales reduction. In an organizational context, however, service quality may refer to services of IT support department and not the IS's service quality itself. Wu \& Wang (Wu and Wang 2006) have criticized the inclusion of this construct in measuring organizational knowledge management systems (KMS) and have argued that service quality is not a good measure of the success of KMS since it determines success rather than being a part of it. Similarly, in their research Urbach et al. (2010), despite of the criticism on the inclusion of service quality construct in measuring success, had included it as a measure of employee portals success; however, results confirmed that service 
staff does not play an important role in the success of organizational employee portals. In addition, many researchers (Petter, DeLone, and McLean 2008; Rosemann and Vessey 2008) have agreed with the criticism on this construct. Hence, in this study we do not take into consideration service quality construct, however, though a new construct named 'collaboration quality' (CQ) which is pertinent to wikis' nature is introduced.

One of the foremost features of wikis is the facilitation of collaboration among their users (Mader 2008; Reinhart 2005). According to Reinhart (2005), the open and collaborative nature of wikis allows communication, teamwork, and documentation of the relevant knowledge in groups. Collaboration involves a synchronized effort of team members to solve a given problem or achieve a common objective (He and Yang 2016; Prokofieva 2013). He and Yang (2016) state that collaboration tasks are different from pooled tasks in that they require high level of dependence and different information needs for group collaboration. They further argue that by working collaboratively, team members perceive outcomes such as effectiveness, efficiency, and performance score. Therefore, while in group or a project, a larger number of people can easily engage in meaningful interactions using wikis (Deering et al. 2008). While the collaborative aspect of an IS was not included in D\&M model, we propose the measure 'collaboration quality' to assess wikis and derive its definition from Urbach et al. (2010) as "the extent to which wikis provide features related to communication, collaboration, information sharing, and social networking among its users".

\subsection{Wiki Use and Satisfaction}

IS use is the extent and way to which users exploit the potential of an IS. Use of an IS can be quantified as amount of use, frequency, nature, appropriateness, extent, and/or purpose of use (Petter, DeLone, and McLean 2008). In this research, we assume wiki use is voluntary; therefore perceived use is considered an adequate measure (Urbach, Smolnik, and Riempp 2010). While users interact with corporate wikis, their attitude towards the system is an indication of their success (Urbach, Smolnik, and Riempp 2010). User satisfaction with wiki system features determines how content the users are with its use. The success dimensions for an IS evaluation is dependent upon the features offered by the respective IS. Hence, success of wiki systems can be effectively determined by analysing users' attitude towards the collaboration, information, and technical features it offers.

\section{$2.3 \quad$ Net benefits with Wiki Use}

The degree to which IS use is thought to bring success to individuals users, groups, or organizations is defined as the net benefits obtained in D\&M model. DeLone and McLean (2003) argue that this construct identifies three main concerns, that is, (i) what meets the criteria as a benefit?; (ii) for whom?; and (iii) at what level of investigation? The term net impact has also been used in the literature to depict net benefits. According to them, the selection of where these impacts should be determined depends upon the type of IS under investigation and its purpose. Researchers have measured net impacts on various levels ranging from individual benefits to group and organizational level benefits. The impact of an IS is a sign that it has provided the user with a better comprehension of decision making context and enhanced productivity (DeLone and McLean 1992). In our study, we have investigated net benefits achieved on individual level with corporate wiki use. Individual level benefits have been mainly associated with individual performance and can be a measure of enhanced efficiency, improved decision making, learning, and/or awareness etc. (Sedera, Gable, and Chan 2004). 


\section{Research Model}

To evaluate enterprise wikis success and their impacts on end-users' performance we propose a research model consisting of the factors related to perceived wiki success determinants. These factors include the quality of collaborative features provided by wikis for collaboration and communication on given tasks (CQ), the general quality of output or information (IQ), and the technical quality of system (SQ) to perform group tasks. We propose that CQ, IQ, and SQ have an impact on the performance of wiki user, which is the perceived net benefits achieved. This relation is mediated by wiki use and wiki user satisfaction. The conceptual model of research is primarily based on the recommendation of DeLone and McLean (1992). All the variables are further evaluated in a multi-dimensional way and are described following.

\subsection{Collaboration quality}

Researchers have mentioned use of wikis in workplace for collaboration e.g., in geographically dispersed teams for software development and project management (Tapscott and Williams 2006; Xiao, Chi, and Yang 2007). He and Yang (2016) argue that collaboration requires good amount of time to carry out mutual tasks and hence much frequent communication. They further state that such collaboration needs information transmission, knowledge sharing, communication, and coordination among users and is related to the recent advancement in technologies. They argue that there is a growing need to evaluate new technologies, such as wikis, in such perspective. Good collaborative features of wikis include easy communication and sharing of information with other users, and ease in updating of editing documents collaboratively. Parmaxi and Zaphiris (2015) established that asynchronous communication supported by wikis help a group in creating a single artefact together. According to a study on wiki use in new product development, efficient collaboration among users via wikis led to higher frequency of usage (Reid et al. 2016). Following the argument of Urbach et al. (2010), we argue that higher the CQ of wikis, the more satisfied will be their users and will engage in their usage. Furthermore, if the users perceive wikis as providing them with high quality collaborative features; they are more likely to provide net benefits to end-users. Thus, we propose that CQ of a wiki system has a positive direct and indirect effect (via wiki use and wiki user satisfaction) on perceived net benefits of end-users and helps users in carrying out their work in a more effective and efficient manner.

\subsection{Information quality}

IQ is defined as the quality of documentation produced by wiki end-users in a collaborative fashion. IQ has always been considered an important aspect of IS evaluation, though it is of much importance in wikis since multiple users are involved in creating and editing information simultaneously and is therefore continuously changing. According to Fehrenbacher (2016), IQ issues are becoming more prevalent and users must be asked to evaluate the appropriateness of data at hand for assessing IQ. The measures of IQ include dimensions such as information accuracy, completeness, currency, format, and usefulness of information (Nelson, Todd, and Wixom 2005). Gohr et al. (2010) state that implementation of wikis lets users to be a part of information editing. As the wiki grows over time, reorganizing and restructuring of information may cause it to be outdated, wrong, inaccurate, and obsolete. Thus, it is hypothesized that high quality information perception leads to high end-user satisfaction and more wiki use. Moreover, good quality of information helps users in executing their tasks rightly and in lesser time. It also helps them to improve their skills as users can enhance their skills by learning from knowledge shared by others. Therefore, we argue that IQ has an impact on perceived individual benefits. 
To capture the various aspects of IQ, it has been taken as a multidimensional concept in this research.

The first dimension to measure IQ, timeliness [TIME] reflects the fact that all wiki users are involved in the process of document creation by editing, deleting old and/or adding new information. Timeliness is classified as a contextual measure of IQ (Lee et al. 2002). According to Friberg \& Reinhart (2009), timeliness of information in enterprise wikis is a significant measure as wiki-edited documents are assigned timestamps whenever they are modified. One of the basic requirements of deploying wikis is to make the information as current as possible by giving the rights to every member of the community to add to or edit existing information. The second dimension of IQ, named relevance [RELEV], is concerned with issues such as relevance, clarity, and goodness of information. It is important in a corporate setting for the users to acquire relevant information to perform their tasks in a better way. Particularly, in a project setting, the relevance of information with respect to project tasks would enhance user satisfaction level. Since corporate wikis have less anonymity in information-sharing as compared to public wikis (Poole and Grudin 2010), we argue that a consensus of users on information redundancy can actually provide the right information status. Another important aspect of IQ is accuracy [ACY]. While, much of debate has been done on the accuracy of information on Wikipedia, Hasan \& Pfaff (2006) argue that firms' internal wikis have less contentious information. This is because of the incorporation of documents' revision control tracking. Format [FORM] is another important dimension classified as a representational measure of IQ. Since multiple authors are editing information, the ability of wikis to provide templates for a comprehensible format is important (Philip et al. 2009). Finally, Usefulness [USE] is also considered a part of IQ, since the information that users receive from wikis must be perceived helpful in order to perform their tasks collaboratively. It represents the intensity with which wiki users believe that information provided by system will increase their job performance.

\subsection{System quality}

SQ refers to wikis' technical performance such as functionality and usability (Lee et al. 2002). Studies (Etezadi-Amoli and Farhoomand 1996; Goodhue 1995) have shown direct positive association of SQ and individual performance. Research also depicts a positive relationship between quality of IS and system usage, e.g., perceived ease of use has shown to be positively related to system dependence (Kositanurit, Ngwenyama, and Osei-Bryson 2006). Users are more likely to use wikis if they perceive them to be easy to use (Waldrop 2008). We propose that SQ of enterprise wikis has a positive influence on user's satisfaction as suggested by Iivari (2005). Finally, we also propose that SQ has a positive impact on perceived net benefits since research suggests a relationship between perceived usefulness of the system and its perceived ease of use (Po-An Hsieh and Wang 2007). Therefore, the quality of enterprise wiki system has a direct positive effect on perceived individual performance and also has an indirect positive effect via wiki use and wiki user satisfaction.

SQ is also a multidimensional concept and researchers have suggested various measures. The first dimension of SQ, accessibility [ACC], is the consistency of a system to be accessible by users. According to Gohr et al. (2010), the problem of accessing information in wikis may arise as the system grows to a large number of engaged users in a firm. Ease of use [EOU] describes the level of physical and mental effort required in the use of a system (Davis, Bagozzi, and Warshaw 1989). In an enterprise wiki system, the ease of use refers to user perceptions concerning its friendliness of use, ease of access, simple layout, and technical operations. The third dimension, reliability [RELIAB], refers to the technical availability of wikis. Nelson et al.(2005) give the example of a user who uses the system once in a week and finds the system 
unavailable due to technical reasons; this would at once reduce his perceived reliability of the system. The last dimension of SQ is concerned with the interactivity [INTERACT] of wikis. In IS research, this measure has been mostly used to evaluate the websites in order to analyse their designs and interactions with the website users (Palmer 2002). We believe that since wikis are based on web pages internal to the firm, and the users interact with the system very frequently, therefore successful interaction with the wikis determines good system quality.

\subsection{Wiki use}

Use of information system is one of the most frequently reported measures of IS success. Even though, wikis are open to all participants, some users are more likely to edit or add content while others focus on information retrieval or reading. Based on the argument of Trkman \& Trkman (2009), we refer to the former as 'active users' while the later as 'passive users' of wikis. Active use $[\mathrm{AU}]$ refers to creating new knowledge by either updating existing contents or creating new pages from scratch, while passive use [PU] is only reading the existing information. As Shang et al. (2016) argue that large number of document viewing in collaborative systems does not necessarily ensure high levels of information sharing. Some users could only be just viewers. Literature suggests IS use has significant positive effect on individual performance such as improved decision making (Yuthas and Young 1998). Urbach et el. (2010) found that employee portals' use to be helpful in improved productivity, efficiency, and effectiveness of employees. Hence, we propose the hypothesis that enterprise wikis use and satisfaction will lead to better individual performance and therefore mediate the relationship between perceived wiki quality and perceived end-user performance.

\subsection{Wiki user satisfaction}

IS end-user satisfaction has been considered a significant metric in measuring IS success. McKinney et al. (2002) noted that although many studies do not explicitly separate information and system features when identifying the structure and dimensionality of the user-satisfaction construct, DeLone and McLean (1992) made an explicit distinction between information aspects and system features as determinants of satisfaction. Our research proposes three dimension of user satisfaction namely collaboration satisfaction [COLLSAT], information satisfaction [INFOSAT], and system satisfaction [SYSSAT] hence capturing user satisfaction with all aspects of wikis. It is proposed that user satisfaction has a positive effect on end-user's job performance based on the findings of past research such as Petter et al. (2008) and Urbach et al. (2010). Therefore, wiki end-user satisfaction mediates the relationship between perceived wiki quality and perceived end-user performance.

\subsection{Perceived individual performance}

The dependent level of analysis is concerned with perceived net benefits gained with enterprise wikis use. Net benefits have been measured with respect to individual benefits gained i.e., improved productivity and professional competency. In a study, conducted by Ou et al. (2016), on interactive knowledge systems and their impacts, knowledge sharing outcomes were measured by individual work performance and collective network efficacy. They defined individual work performance in terms of confidence, productivity, decision making, and work quality. In our study, three dimensions namely, efficiency, effectiveness, and capacity development have been taken into consideration. Efficiency [EFF] is defined as executing a task in a lesser time with IS use than without it (Jain and Kanungo 2005), which is a measure of enhanced individual performance. According to a study by Arazy et al. (2009) corporate wiki users reported ease in work and enhanced productivity. Effectiveness [EFT] refers to the 
improvement in quality of work done with IS use (Goodhue and Thompson 1995). Pentland (1989) has also suggested effectiveness as a dimension of end-user performance. The final measure of individual performance is capacity or competence development [CAP], which is the development of new skills and knowledge of users. Since wikis are collaborative in nature, therefore they increase the likelihood of skill development as users frequently interact with others, share knowledge, and learn mutually (Cress and Kimmerle 2008).

Based on the above arguments, we propose the following hypotheses to be further empirically tested:

$\mathrm{H}_{1 \mathrm{~A}}$ : Collaboration Quality of wikis has a direct positively significant effect on perceived individual performance

$\mathrm{H}_{1 \mathrm{~B}}$ : Collaboration Quality of wikis has an indirect positively significant effect on perceived individual performance via wiki use and wiki user satisfaction

$\mathrm{H}_{2 \mathrm{~A}}$ : Information Quality of wikis has a direct positively significant effect on perceived individual performance

$\mathrm{H}_{2 \mathrm{~B}}$ : Information Quality of wikis has an indirect positively significant effect on perceived individual performance via wiki use and wiki user satisfaction

$\mathrm{H}_{3 \mathrm{~A}}$ : System Quality of wikis has a direct positively significant effect on perceived individual performance

$\mathrm{H}_{3 \mathrm{~B}}$ : System Quality of wikis has an indirect positively significant effect on perceived individual performance via wiki use and wiki user satisfaction

Figure 1 Proposed conceptual research model

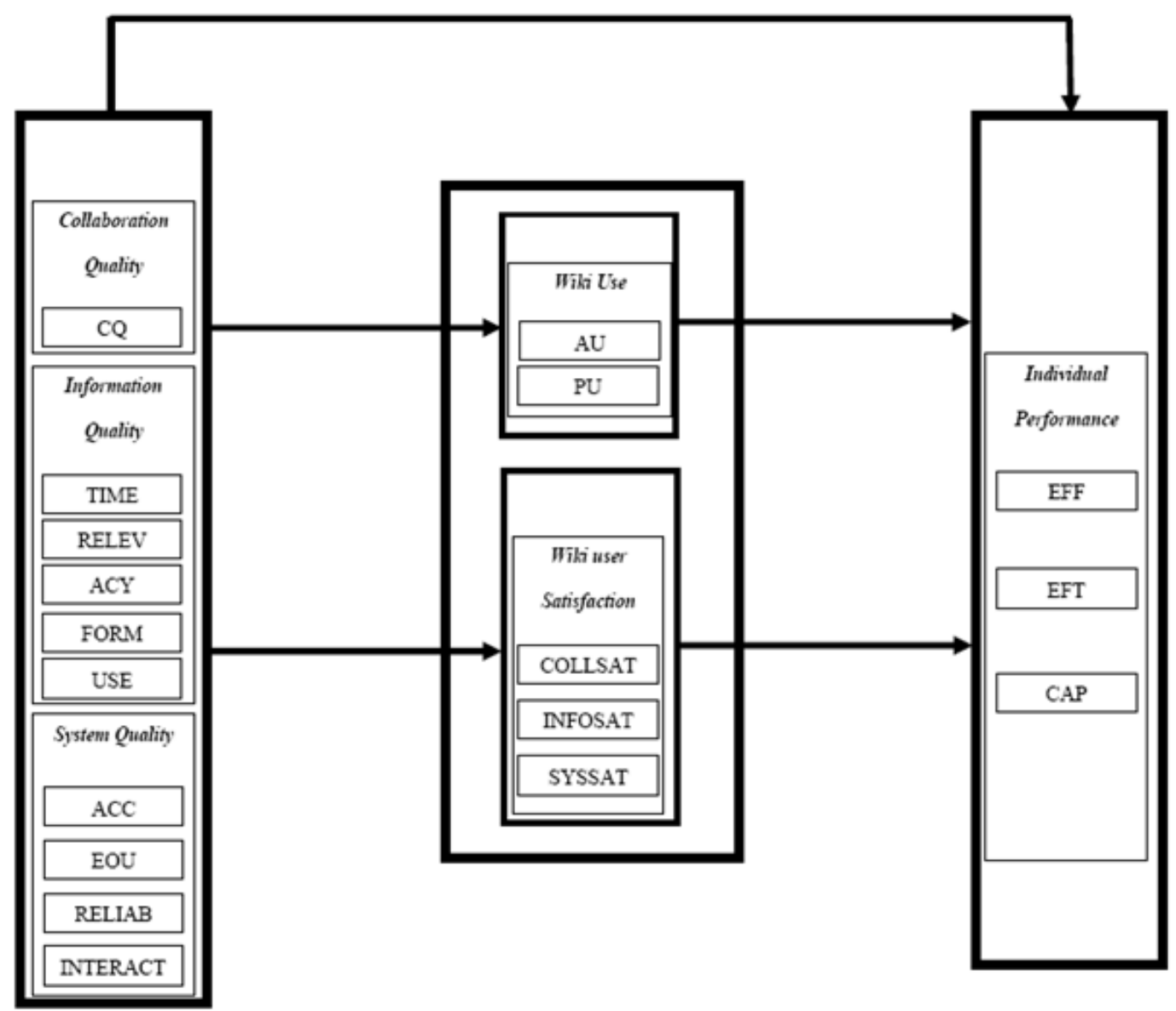




\section{Research Methodology}

\subsection{Data collection and Sample}

Multinational high-tech firms (operating in software and hardware industries) using enterprise wikis were identified. The firms were considered because they are leading firms in technological sector namely Accenture, Atlassian, Cisco, Comptel, Ericsson, General Electric, Hewlett Packard, IBM, JDSU, Telenor, T-Mobil, XWiki, and Yahoo. Wiki users in these firms were sent an online link with the help of senior management to fill in the survey (see Appendix I). All the organizations were using wikis for at least more than a year. During pre-testing, the questionnaire was tested with the technical professional users of enterprise wikis. Majority of the constructs were adapted from existing scales and modified contextually. Wordings of some items/indicators were changed after pilot testing, especially for new items that were incorporated for the constructs collaboration quality, active use, and passive use. A brief description of research was given with the questionnaire link in the emails gathering data.

A total of 181 responses were obtained out of which 4 cases were removed as multivariate outliers leaving us with 177 valid responses. The demographics of sample are displayed in Table 1. A disparity in gender percentage might be because of the range of activities performed by the high-tech firms that attract more males than females in the industry.

Table 1 Sample Demographic Composition $(\mathbf{N}=177)$

\begin{tabular}{|c|c|c|c|}
\hline Characteristic & Items & Number & Percentage \\
\hline Gender & $\begin{array}{l}\text { Female } \\
\text { Male }\end{array}$ & $\begin{array}{l}35 \\
142\end{array}$ & $\begin{array}{l}19.8 \\
80.2\end{array}$ \\
\hline Age & $\begin{array}{l}<20 \\
20-29 \\
30-39 \\
40-49 \\
50 \text { or above }\end{array}$ & $\begin{array}{l}0 \\
60 \\
54 \\
40 \\
23\end{array}$ & $\begin{array}{l}0 \\
33.9 \\
30.5 \\
22.6 \\
13.0\end{array}$ \\
\hline Level of Education & $\begin{array}{l}\text { High School } \\
\text { Bachelor Degree } \\
\text { Master Degree } \\
\text { Ph.D. }\end{array}$ & $\begin{array}{l}9 \\
82 \\
71 \\
15\end{array}$ & $\begin{array}{l}5.1 \\
46.3 \\
40.1 \\
8.5\end{array}$ \\
\hline Level of experience with Wikis & $\begin{array}{l}<6 \text { months } \\
6 \text { months- } 1 \text { year } \\
1-2 \text { years } \\
2-5 \text { years } \\
>5 \text { years }\end{array}$ & $\begin{array}{l}4 \\
3 \\
6 \\
85 \\
79\end{array}$ & $\begin{array}{l}2.3 \\
1.7 \\
3.4 \\
48.0 \\
44.6\end{array}$ \\
\hline Job Position & $\begin{array}{l}\text { General Staff } \\
\text { Supervisory Staff } \\
\text { Middle Management } \\
\text { Senior Management }\end{array}$ & $\begin{array}{l}76 \\
35 \\
46 \\
20\end{array}$ & $\begin{array}{l}42.9 \\
19.8 \\
26.0 \\
11.3\end{array}$ \\
\hline Firm Size (No. of employees) & $\begin{array}{l}<100 \\
100-500 \\
500-1000 \\
>1000\end{array}$ & $\begin{array}{l}52 \\
26 \\
19 \\
80\end{array}$ & $\begin{array}{l}29.4 \\
14.7 \\
10.7 \\
45.2\end{array}$ \\
\hline
\end{tabular}

\subsection{Construct measurement}

All research variables were measured using multi-item scales adapted from past research (see Appendix II). All Items employed a 5-point Likert scale where $1=$ 'strongly disagree' to $5=$ 
'strongly agree' except for AU3 and PU3 where $1=$ 'very low' to $5=$ 'very high'. Items related to system collaboration satisfaction, information satisfaction, and system satisfaction were measured on 1 = 'highly dissatisfied' to $5=$ 'highly satisfied'. A pilot study was conducted to establish the validity of scales. Scales for timeliness, relevance, accuracy, format, usefulness, and accessibility, ease of use, reliability, interactivity, collaboration satisfaction, information satisfaction, and system satisfaction were adapted from (Lee et al. 2002; Nelson, Todd, and Wixom 2005; McKinney, Yoon, and Mariam Zahedi 2002). Measurement items for scales of active use and passive use were adapted from (Davis 1989; Igbaria et al. 1997). Finally, the scales for three variables of individual performance namely efficiency, effectiveness, and capacity development were adapted from (Pentland 1989; Goodhue and Thompson 1995; Etezadi-Amoli and Farhoomand 1996; Torkzadeh and Doll 1999; Igbaria and Baroudi 1995).

\section{Data analysis and results}

The data analysis and hypotheses testing were conducted using SPSS and AMOS software packages. Initially, data was screened for missing values, descriptive statistics, multivariate outliers, normality, homoscedasticity, multi-collinearity, and correlations. Convergent validity, discriminant validity, and reliability were determined in the next step for each construct prior to hypotheses testing.

\subsection{Scale validity and reliability}

We tested the constructs for uni-dimensionality, convergent validity, discriminant validity, and internal consistency reliability (see Appendix).. Uni-dimensionality was established by exploratory factory analysis (EFA) with varimax rotation. Two items (CQ3 and CQ5) of the construct 'collaboration quality' were dropped due to low factor loadings and communalities following the guidelines of Gefen and Straub (2005). Uni-dimensionality and convergent validity was established for all constructs.

Following this, the constructs were tested for discriminant validity. Items which cross loaded on other constructs were removed. One item (ACC2) of the construct 'accessibility' and one item (EFT1) of the construct 'effectiveness' were dropped due to high cross loadings. Fornell and Larcker's (1981) criteria is used to test discriminant validity by comparing the AVE value to the shared variance of two constructs with EFA. The constructs 'relevance' [RELEV] and 'usefulness' [USE] were merged into single variables named [RELEV_USE] since discriminant validity was not established between the two. This is perhaps due to the reason that individuals perceive information provided by wiki to be useful only if it is relevant to their work needs. Similar findings were observed for variables 'accessibility' [ACC] and 'ease of use' [EOU], which were merged into [ACC_EOU]. This might be due to conceptual similarities and overlapping between these two variables. This shows that end-users perceive wiki system to be user friendly if the system is easily accessible or quick to access. Discriminant analysis also revealed that 'active use' [AU] and 'passive use' [PU] were not considered as distinct factors by respondents, therefore, merged into a single factor [AU_PU]. This implies that individuals use wiki system for both retrieving and sharing information; if users are retrieving information via wikis, they are likely to share the information as well. 'Collaboration satisfaction' [COLLSAT] and 'information satisfaction' [INFOSAT] were also merged into [COLLSAT_INFOSAT]. We infer that end-users who are satisfied with the quality of information provided, also feel satisfied to its collaborative features as the information is built collaboratively. Finally, at the dependent level, discriminant analysis revealed that 'efficiency' $[\mathrm{EFF}]$ and effectiveness' [EFT] did not discriminate as perceived by wiki users and therefore merged into a single variable [EFF_EFT]. This means the improvement in work speed and quality of task is perceived to be similar. Factor structures were confirmed with confirmatory 
factor analysis (CFA). Convergent and discriminant validities were also established with CFA. According to Hair et al. (2010), discriminant validity is established when maximum shared variance (MSV) and average shared variance (ASV) values are less than AVE. We used the index of Cronbach's Alpha $(\alpha)$ (Cronbach 1951) to test the reliability of constructs. All values were above the 0.7 threshold recommended by Hair et al. (2010). Results of convergent validity, discriminant validity, and reliability are presented in Appendix II. It table also shows the coding used in data analysis for all constructs and their respective items.

\subsection{Hypotheses Testing}

Hypotheses testing was done using PROCESS macro for SPSS (Hayes 2013). The result of hypotheses testing of all direct relations on perceived individual performance (efficiency/effectiveness and capacity development) as well as indirect relations via mediators (wiki use and wiki user satisfaction) are shown in Table 2. It should be noted that PROCESS macro output gives un-standardized $\beta$ co-efficient, hence standard error values are provided corresponding to each $\beta$ estimate.

Table 2 Synthesis of results for direct and indirect relations

\begin{tabular}{|c|c|c|c|c|c|}
\hline \multicolumn{6}{|c|}{ DEPENDENT VARIABLE: EFF_EFT } \\
\hline Independent Var. & $\mathrm{DE}$ & IE via (AU_PU) & $\begin{array}{l}\text { IE via } \\
\text { (COLLSAT INFOSAT) }\end{array}$ & IE via (SYSSAT) & TE \\
\hline CQ & .095 & .250 & .170 & .021 & 0.536 \\
\hline$S E$ & .063 & .047 & .052 & .040 & .063 \\
\hline$L L / U L$ & $.410 / .662$ & $.170 / .357$ & $.084 / .294$ & $-.053 / .105$ & $.410 / .662$ \\
\hline TIME & .086 & .217 & .185 & .022 & .512 \\
\hline$S E$ & .057 & .046 & .058 & .044 & .057 \\
\hline$L L / U L$ & $-.026 / .200$ & $.138 / .323$ & $.083 / .316$ & $-.068 / .109$ & $.383 / .640$ \\
\hline RELEV_USE & .200 & .262 & .169 & .019 & .652 \\
\hline$S E$ & .062 & .058 & .054 & .043 & .057 \\
\hline$L L / U L$ & $.077 / .322$ & $.165 / .396$ & $.082 / .294$ & $-.070 / .101$ & $.538 / .765$ \\
\hline ACY & .060 & .117 & .168 & .017 & .364 \\
\hline$S E$ & .054 & .041 & .049 & .041 & .070 \\
\hline$L L / U L$ & $-.046 / .167$ & $.040 / .200$ & $.085 / .277$ & $-.062 / .101$ & $.225 / .503$ \\
\hline FORM & .070 & .154 & .192 & .016 & .433 \\
\hline$S E$ & .058 & .040 & .052 & .049 & .068 \\
\hline$L L / U L$ & $-.044 / .185$ & $.082 / .240$ & $.090 / .302$ & $-.086 / .109$ & $.298 / .567$ \\
\hline ACC_EOU & .060 & .205 & .229 & .014 & .509 \\
\hline$S E$ & .069 & .046 & .061 & .066 & .065 \\
\hline$L L / U L$ & $-.077 / .197$ & $.122 / .309$ & $.116 / .359$ & $-.114 / .147$ & $.381 / .637$ \\
\hline RELIAB & -.109 & .180 & .139 & .069 & .281 \\
\hline$S E$ & .056 & .046 & .043 & .055 & .072 \\
\hline$L L / U L$ & $-.220 / .002$ & $.097 / .278$ & $.066 / .237$ & $-.039 / .177$ & $.138 / .424$ \\
\hline INTERACT & .091 & .281 & .194 & .016 & .583 \\
\hline$S E$ & .062 & .051 & .052 & .049 & .061 \\
\hline$L L / U L$ & $-.031 / .215$ & $.192 / .395$ & $.097 / .307$ & $-.079 / .113$ & $.462 / .704$ \\
\hline \multicolumn{6}{|c|}{ DEPENDENT VARIABLE: CAP } \\
\hline Independent Var. & $\mathrm{DE}$ & IE via (AU_PU) & $\begin{array}{l}\text { IE via } \\
\text { (COLLSAT_INFOSAT) }\end{array}$ & IE via (SYSSAT) & TE \\
\hline CQ & .293 & .121 & .119 & -.012 & .522 \\
\hline$S E$ & .075 & .047 & .057 & .051 & .064 \\
\hline$L L / U L$ & $.144 / .443$ & $.039 / .229$ & $.011 / .241$ & $-.117 / .082$ & $.395 / .649$ \\
\hline TIME & .143 & .136 & .148 & -.012 & .415 \\
\hline$S E$ & .078 & .044 & .071 & .055 & .068 \\
\hline$L L / U L$ & $-.011 / .298$ & $.063 / .237$ & $.021 / .304$ & $-.122 / .102$ & $.280 / .551$ \\
\hline RELEV_USE & .301 & .117 & .137 & -.018 & .538 \\
\hline$S E$ & .084 & .066 & .065 & .058 & .063 \\
\hline$L L / U L$ & $.134 / .468$ & $-.009 / .251$ & $.013 / .271$ & $-.138 / .094$ & $.412 / .664$ \\
\hline ACY & .168 & .080 & .126 & -.023 & .351 \\
\hline$S E$ & .073 & .034 & .059 & .054 & .070 \\
\hline$L L / U L$ & $.023 / .312$ & $.024 / .164$ & $.012 / .245$ & $-.127 / .087$ & $.211 / .490$ \\
\hline FORM & .096 & .102 & .165 & -.030 & .334 \\
\hline$S E$ & .079 & .036 & .065 & .068 & .071 \\
\hline
\end{tabular}




\begin{tabular}{llllll}
$L L / U L$ & $-.061 / .254$ & $.043 / .184$ & $.037 / .299$ & $-.171 / .098$ & $.194 / .475$ \\
ACC_EOU & $\mathbf{. 1 1 6}$ & $\mathbf{. 1 3 6}$ & $\mathbf{. 1 9 4}$ & $\mathbf{- . 0 5 9}$ & $\mathbf{. 3 8 6}$ \\
SE & .095 & .042 & .077 & .089 & .069 \\
$L L / U L$ & $-.072 / .304$ & $.065 / .233$ & $.040 / .347$ & $-.232 / .120$ & $.249 / .524$ \\
RELIAB & $\mathbf{- . 0 6 3}$ & $\mathbf{. 1 1 9}$ & $\mathbf{. 1 2 7}$ & $\mathbf{. 0 1 0}$ & .078 \\
$S E$ & .078 & .043 & .052 &. .193 \\
$L L / U L$ & $-.217 / .091$ & $.051 / .223$ & $.037 / .246$ & .074 \\
INTERACT & $\mathbf{. 0 9 6}$ & $\mathbf{. 1 7 7}$ & $\mathbf{. 1 7 2}$ &. .025 & $.047 / .340$ \\
$S E$ & .086 & .054 & .063 & .067 & .068 \\
$L L / U L$ & $-.073 / .266$ & $.073 / .290$ & $.054 / .305$ & $-.159 / .106$ & $.285 / .556$ \\
\hline
\end{tabular}

Note. Note. $\beta$ Values are un-standardized estimates; Standard errors (SE) are provided with $\beta$ estimates LL: Lower limit of confidence interval; UL: Upper limit of confidence interval

The above table shows all the direct and indirect path with significant paths highlighted. All six hypotheses $\mathrm{H}_{1 \mathrm{~A}}, \mathrm{H}_{1 \mathrm{~B}}, \mathrm{H}_{2 \mathrm{~A}}, \mathrm{H}_{2 \mathrm{~B}}, \mathrm{H}_{3 \mathrm{~A}}$, and $\mathrm{H}_{3 \mathrm{~B}}$, were tested subsequently. $\mathrm{H}_{1 \mathrm{~A}}$ concerns with the direct effect of CQ on perceived individual performance. Table 2 shows that $\mathrm{CQ}$ has a direct effect on EFF_EFT $(\beta=.095 ; L L=.410, U L=.662)$ as well as on CAP $(\beta=.293 ; L L=.144$, $U L=.443)$. Hence, $\mathrm{H}_{1 \mathrm{~A}}$ is accepted. $\mathrm{H}_{1 \mathrm{~B}}$ deals with the indirect effect of $\mathrm{CQ}$ on perceived individual performance. From Table 2, we can see that CQ has a significant indirect effect on EFF_EFT via AU_PU $(\beta=.250 ; L L=.170, U L=.357)$ and COLLSAT_INFOSAT $(\beta=.170$; $L L=.084, U L=.294)$ while the indirect effect via SYSSAT was not found to be significant. Similarly, CQ was also found to have significant indirect effect on CAP via AU_PU $(\beta=.121$; $L L=.039, U L=.229)$ and COLLSAT_INFOSAT $(\beta=.119 ; L L=.011, U L=.241)$ but no effect was found via SYSSAT. Hence, $\mathrm{H}_{1 \mathrm{~B}}$ is also accepted.

Hypothesis $\mathrm{H}_{2 \mathrm{~A}}$ proposes a direct effect of IQ on perceived individual performance. Since IQ is measured with multiple dimensions, therefore, Table 2 shows the effects of all dimensions on EFF_EFT and CAP. Out of the four dimensions (TIME, RELEV_USE, ACY, and FORM) of IQ, only RELEV_USE $(\beta=.200 ; L L=.077, U L=.322)$ has a significant direct effect on EFF_EFT, while only RELEV_USE $(\beta=.301 ; L L=.134, U L=.468)$ and ACY $(\beta=.168$; $L L=.023, U L=.312$ ) have direct effects on CAP. The hypothesis $\mathrm{H}_{2 \mathrm{~A}}$ for direct effect of IQ on perceived individual performance is accepted. Hypothesis $\mathrm{H}_{2 \mathrm{~B}}$ proposes an indirect effect of IQ on perceived individual performance. Results indicate that all four dimensions of IQ, that is, TIME $(\beta=.217 ; L L=.138, U L=.323)(\beta=.185 ; L L=.083, U L=.316)$, RELEV_USE $(\beta=.262$; $L L=.165, U L=.396)(\beta=.169 ; L L=.082, U L=.294), \operatorname{ACY}(\beta=.117 ; L L=.040, U L=.200)$ $(\beta=.168 ; L L=.085, U L=.277)$, and FORM $(\beta=.154 ; L L=.082, U L=.240)(\beta=.192 ; L L=.090$, $U L=.302$ ) have positive significant effect via AU_PU and COLLSAT_INFOSAT on EFF_EFT, respectively. There was not a single significant indirect effect via SYSSAT on EFF_EFT. As far as the indirect effects on CAP are concerned, only RELEV_USE did not have a significant impact via AU_PU. The effects were such that TIME $(\beta=.136 ; L L=.063$, $U L=.237) \quad(\beta=.148 ; \quad L L=.021, \quad U L=.304), \quad R E L E V \_U S E(\beta=.117 ; \quad L L=-.009, \quad U L=.251)$ $(\beta=.137 ; \quad L L=.013, \quad U L=.271), \operatorname{ACY}(\beta=.080 ; L L=.024, \quad U L=.164)(\beta=.126 ; L L=.012$, $U L=.245)$, and FORM $(\beta=.102 ; L L=.043, U L=.184)(\beta=.165 ; L L=.037, U L=.299)$ AU_PU and COLLSAT_INFOSAT, respectively. Once again, there was no significant indirect via SYSSAT. Thus, we conclude the acceptance of hypothesis $\mathrm{H}_{2 \mathrm{~B}}$.

Hypothesis $\mathrm{H}_{3 \mathrm{~A}}$ suggests a direct effect of $\mathrm{SQ}$ on perceived individual performance. Of the three dimension of SQ, none has a significant impact on EFF_EFT or CAP. Hence, hypothesis $\mathrm{H}_{3 \mathrm{~A}}$ is rejected. Finally, the hypothesis $\mathrm{H}_{3 \text { в }}$ proposes an indirect effect of SQ on perceived individual performance. All three dimensions of SQ that is, ACC_EOU $(\beta=.205 ; L L=.122, U L=.309)$ $(\beta=.229 ; L L=.116, U L=.359)$, RELIAB $(\beta=.180 ; L L=.097, U L=.278)(\beta=.139 ; L L=.066$, $U L=.359)$, and INTERACT $(\beta=.281 ; L L=.192, U L=.395)(\beta=.194 ; L L=.097, U L=.307)$ have indirect effects via AU_PU and COLLSAT_INFOSAT, respectively. However, there is significant indirect effect via SYSSAT on EFF_EFT, whatsoever. Concerning CAP, again all three dimensions of SQ that is ACC_EOU $(\beta=.136 ; L L=.065, U L=.233)(\beta=.195=4 ; L L=.040$, 
$U L=.347), \quad$ RELIAB $(\beta=.119 ; L L=.051, \quad U L=.223)(\beta=.127 ; L L=.037, \quad U L=.246)$, and INTERACT $(\beta=.177 ; L L=.073, U L=.290)(\beta=.172 ; L L=.054, U L=.305)$ have indirect effects via AU_PU and COLLSAT_INFOSAT, respectively. There is no indirect significant effect on CAP via SYSSAT. Hypotheses $\mathrm{H}_{3 \mathrm{~B}}$ is hence accepted.

\section{Discussion}

This study focuses on the problem of measuring the success of corporate wikis from the endusers perspective. Our results supported the validity of our proposed research model for measuring wiki systems impacts on individual performance in corporate environment. Results show that collaboration quality, information quality, and system quality of wikis enhance their use and end-user satisfaction and in turn impact individual performance.

Collaboration quality provided by wikis was found to enhance users' efficiency, effectiveness, as well as enhances their capacity development. The quality of collaborative functionalities of a wiki system which includes easy communication, sharing of information, and effective social networking with colleagues helps in improved individual performance. Better collaborative features facilitate active participation and user satisfaction in terms of both information collection and sharing which leads to improved performance. As employees use wikis to collaborate with their colleagues, they are better able to perform their work both in terms of time and quality since collaboration enables crowd-sourcing. This is consistent with the findings of Urbach et al. (2010) concerning employee portals. Results also suggest good wiki collaboration features play a positive role in users' capacity development. Since, collaborative features allow users to connect with their colleagues and communicate with them; they provide users opportunities to enhance their work related knowledge and learn from others. This is perhaps because capacity development is related to users' learning over the period of time and collaborating with others increases the likelihood of learning from others. Collaboration quality also has a direct impact on individual performance, which indicate that their might some other underlying factors establishing this link.

Our findings suggest that information quality is also an important factor in determining corporate wiki success and enhances individual performance. Timeliness of information was found to impact individual efficiency and capacity development via both wiki use and collaboration/information satisfaction. As users perceive that wiki is providing them with upto-date information they refer to it more often thus increasing its usage. Similar findings were observed with user satisfaction concerning collaboration and information. Up-to-date information affects user satisfaction positively. This is in line with the past research findings with other technologies (Wu and Wang 2006; Negash, Ryan, and Igbaria 2003). In corporate environment, up-to-date information is critical since obsolete information may result in poor financial performance. Information relevance and usefulness is another important factor deciding wiki success. It is interesting to see that users consider only that information as useful which they consider relevant to their work. Besides, information relevant to users' task at work leads to more wiki usage both in terms of sharing and retrieving information and they also feel more satisfied with the wiki. Hsu et al. (Hsu, Yen, and Chung 2015) and Stefanovic et al. (Stefanovic et al. 2016) had similar findings while assessing ERP post implementation success and e-government systems, respectively. Users believe work relevant information provided by the wiki enhances their efficiency, effectiveness with increased usage and satisfaction. We believe this is because finding relevant information saves times for users to search it elsewhere and thus make enables users to execute tasks much efficiently and effectively. However, users do not consider active use of wikis for their capacity development, hence the mediation via use was not found significant. In addition, such information also is beneficial in increasing users' knowledge about their work related tasks and therefore they can hone their skills. Similarly, 
accuracy of information and format also have a positive effect on individual performance. Users feel satisfied with information and collaboration in wiki if the information provided is accurate which might help them in work efficiency (Stefanovic et al. 2016). It should be noted that there no mediation via system satisfaction for any of the IQ constructs. A possible explanation of this hypothesis being rejected is that most systems used by high-tech firms are state-of-the-art systems and hence taken for granted as they almost always perform up to the mark.

System quality variables did not have any direct effect on individual performance, however, all constructs were found to have significant indirect effects via use and information/collaborations satisfaction. An easy to use system therefore leads to more wiki use and collaboration/ information satisfaction as they might feel pleased with the level of collaboration and information provided by such a system. This in turn enhances their work efficiency. Similarly, reliability of the system is also important for users as they might believe it is important the system be available to them at all times. Users might look for information or as solution to problems in documentations to perform their work and enhance their capabilities. A reliable system allows this by letting users not to lose time. Interactivity was found to have the strongest impact perceived efficiency/effectiveness and capacity development of wiki end-users via both wiki use and wiki collaboration/information satisfaction. The findings suggest that the more interactive a system is; more satisfied are the users with the collaboration and information. Shang et al. (2016) have mentioned that in wiki-based platforms, the scope of their features permit users to feel being part of the community and share knowledge. An interactive wiki system enables active participation in information sharing and creation and therefore enhances user's satisfaction related to collaboration/information. Wikis enable user participation, which can only be possible through a high level of interaction with the system.

\section{Conclusion - Implication, limitations and future research}

The results of our study have implications for both for theory and practice. From a theoretical viewpoint, the study makes an extension to D\&M IS success model and its empirical testing in a different context in comparison with past studies. The extension of D\&M model has been recommended in past research (DeLone and McLean 2003; Iivari 2005; Urbach, Smolnik, and Riempp 2010). The study contributes to theory by testing a success model for corporate wikis and suggests that wiki success is multidimensional in nature. The existing quality measures in D\&M model are inadequate to completely evaluate collaborative systems like wikis and therefore collaboration quality was introduced to gauge their collaborative features. This might be helpful for future researchers to assess other collaborative systems which are making their way into the organizations. Furthermore, while we distinguished between active and passive use of wiki, the user do not identify them as active or passive use. People tend to like the authoring feature of collaborative technologies and like to contribute with them.

The results of our study also have practical implications since our model offers a way for firms to measure and predict success of their internal wikis. Our results suggest that wikis can be used by organizations collaboration among different stakeholders. The results will help companies to improve their existing wiki systems or invest in new systems based upon our results. Besides just focusing on other quality dimensions, it is important to consider the collaborative features of wikis. Corporations can use wikis to enhance their workers' efficiency, effectiveness, as well as their work related skills. Therefore, organizations should focus on features that enhance user satisfaction and increase wiki use such as the collaboration, information, and system features.

The findings of our study should be viewed in light of certain limitations. A first limitation is the choice of only the operational dimensions of wiki success. This limit is due to the nature of assessment and positioning the level of analysis from the end-user's perspective. . However, as 
pointed out by Saunders \& Jones (1992), there are several performance dimensions of IS that could be considered by the researchers including the organizational strategy. Moreover, other variables such as the organizational cultural variables, the management factors and the individual factors are not included that could affect the results. Another limitation is the treatment of net benefits perceived in terms of individual performance. This choice gives a limited impact of the perceived wiki success on the entire organization. It would be beneficial to analyse also the benefits related to the efficiency of the business processes, and improvement in group collaborations etc. The focus could be group, team, or organizational impact as a whole. One limitation concerns the various organizations and cultures involved in our sample since the data collection was done from various firms. Although this is recommended for generalizability but certain contexts (organizational and geographic) may show special circumstances demanding additional considerations. Another limitation to our research is the use of self-reported measures in our survey questionnaire that does not guarantee the reflection of actual use behaviour or the actual effect on individual performance. Moreover, these measures are collected at one point in time that is a cross-sectional design, which makes them prone to mono-method variance and therefore concrete statements about the causality effects cannot be made. We therefore are aware of the limitations associated with the use of selfreported measures and hence the possibility of common method bias. However, we have used Harman's one factor test which is most widely used test for common method bias (CMB). We have applied an exploratory one-factor analysis and examined the un-rotated factor solution. The resulting factor retained explained $39.46 \%$ of the total variance. Furthermore, to avoid common method bias, we used a cover letter for our respondents and ensured anonymity of their responses following the guidelines of Podsakoff et al. (Podsakoff et al. 2003).

The implementation of social tools in firms is growing; wikis being one of them can be beneficial if the technology is deployed smartly. We showed that organizations can use a model based on D\&M IS success model to evaluate their existing wikis. It is important that organizations consider the various features provided by wikis and encourage users to use them for better work performance. As collaboration at workplace is very necessary, especially in case of team tasks and geographically dispersed teams, enterprise wikis can be very helpful in improving collaboration at work. Wikis can help firms in better employee performance and reducing the friction among them. Future research can further focus on collaborative features of wikis and their benefits on groups, teams, and organizational levels. 


\section{References}

Aitamurto, Tanja, and Hélène Landemore. 2015. "Participants' Motivation Factors and Profile In Crowdsourced Law Reform." In The 11th International Symposium on Open Collaboration. San Francisco, USA: ACM.

Arazy, O, I Gellaty, Jang Soobaek, and J Patterson. 2009. "Wiki Deployment in Corporate Settings." Technology and Society Magazine, IEEE, 2009.

Bensing, Fariba. 2015. "The Vienna History Wiki - a Collaborative Knowledge Platform for the City of Vienna." In The 11th International Symposium on Open Collaboration. San Francisco: ACM.

http://www.opensym.org/2015/06/26/the-vienna-history-wiki-a-collaborativeknowledge-platform-for-the-city-of-vienna/.

Bhatti, Zeeshan Ahmed, Serge Baile, and Hina Mahboob Yasin. 2011. "The Success of Corporate Wiki Systems: An End User Perspective.” In , 134-143. WikiSym '11. New York, NY, USA: ACM.

Cress, Ulrike, and Joachim Kimmerle. 2008. "A Systemic and Cognitive View on Collaborative Knowledge Building with Wikis." International Journal of Computer-Supported Collaborative Learning 3 (2):105-22.

Cronbach, Lee J. 1951. "Coefficient Alpha and the Internal Structure of Tests." Psychometrika 16 (3):297-334. https://doi.org/10.1007/BF02310555.

Davis, Fred D. 1989. "Perceived Usefulness, Perceived Ease of Use, and User Acceptance of Information Technology." MIS Quarterly 13 (3):319-40.

Davis, Fred D, Richard P Bagozzi, and Paul R Warshaw. 1989. "User Acceptance of Computer Technology: A Comparison of Two Theoretical Models." Management Science 35 (August):982-1003.

Deering, Anne, Andy Cook, Gillis Jonk, and Anne van Hall. 2008. "Internet Tools Enable Organizational Transformation from the inside out: The Nokia Siemens Networks Case." Strategy \& Leadership 36 (5):34-37. https://doi.org/10.1108/10878570810902103.

DeLone, William H., and Ephraim R. McLean. 1992. "Information Systems Success: The Quest for the Dependent Variable." Information Systems Research 3 (1):60-95.

DeLone, William H, and Ephraim R McLean. 2003. "The DeLone and McLean Model of Information Systems Success: A Ten-Year Update.” Journal of Management Information Systems 19 (April):9-30.

Etezadi-Amoli, Jamshid, and Ali F. Farhoomand. 1996. "A Structural Model of End User Computing Satisfaction and User Performance.” Information \& Management 30 (2):65-73. https://doi.org/10.1016/0378-7206(95)00052-6.

Fehrenbacher, Dennis D. 2016. "Perceptions of Information Quality Dimensions from the Perspective of Commodity Theory." Behaviour \& Information Technology 35 (4):254-67. https://doi.org/10.1080/0144929X.2015.1128974.

Fominykh, Mikhail, Ekaterina Prasolova-Førland, Monica Divitini, and Sobah Abbas Petersen. 2016. "Boundary Objects in Collaborative Work and Learning." Information Systems Frontiers 18 (1):85-102. https://doi.org/10.1007/s10796015-9579-9. 
Fornell, Claes, and David F. Larcker. 1981. "Evaluating Structural Equation Models with Unobservable Variables and Measurement Error." Journal of Marketing Research 18 (1):39-50. https://doi.org/10.2307/3151312.

Friberg, Therese, and Wolfgang Reinhardt. 2009. "An Emipirical Study on Criteria for Assessing Information Quality in Corporate Wikis.” In ICIQ, 217-30. Germany.

Gefen, David, and Detmar Straub. 2005. "A Practical Guide to Factorial Validity Using PLS-Graph: Tutorial and Annotated Example.” ResearchGate 16 (1):91109.

Gohr, Andreas, Detlef Hüttemann, Daniel Faust, and Frank Fuchs-Kittowski. 2010. "Quality Check with DokuWiki for Instant User Feedback." In Proceedings of the 6th International Symposium on Wikis and Open Collaboration, 17:1-17:2. WikiSym '10. New York, NY, USA: ACM. https://doi.org/10.1145/1832772.1832796.

Goodhue, Dale L. 1995. "Understanding User Evaluations of Information Systems." Management Science 41 (12):1827-44.

Goodhue, Dale L., and Ronald L. Thompson. 1995. "Task-Technology Fit and Individual Performance." MIS Quarterly 19 (2):213-36.

Grace, Tay Pei Lyn. 2009. "Wikis as a Knowledge Management Tool." Journal of Knowledge Management 13 (4):64-74.

Hair Jr., Joseph F., William C. Black, Barry J. Barbin, and Rolph E. Anderson. 2010. Multivariate Data Analysis. 7th ed. Prentice Hall.

Hasan, Helen, and Charmaine Pfaff. 2006. "The Wiki: An Environment to Revolutionize Employees' Interaction with Corporate Knowledge.” In Proceedings of the 18th Australia Conference on Computer-Human Interaction, 377-80. Sydney, Australia: ACM.

Hayes, Andrew F. 2013. Introduction to Mediation, Moderation, and Conditional Process Analysis: A Regression-Based Approach. 1 edition. New York: The Guilford Press.

He, Wei, and Lu Yang. 2016. "Using Wikis in Team Collaboration: A Media Capability Perspective." Information \& Management. https://doi.org/10.1016/j.im.2016.06.009.

Heidrich, Balázs, Richárd Kása, Wesley Shu, and Nick Chandler. 2015. "Worlds Apart But Not Alone: How Wiki Technologies Influence Productivity and DecisionMaking in Student Groups." Decision Sciences Journal of Innovative Education 13 (2):221-46. https://doi.org/10.1111/dsji.12062.

Hsu, Pei-Fang, HsiuJu Rebecca Yen, and Jung-Ching Chung. 2015. "Assessing ERP Post-Implementation Success at the Individual Level: Revisiting the Role of Service Quality.” Information \& Management 52 (8):925-42. https://doi.org/10.1016/j.im.2015.06.009.

Igbaria, Magid, and Jack J. Baroudi. 1995. "The Impact of Job Performance Evaluations on Career Advancement Prospects: An Examination of Gender Differences in the IS Workplace." MIS Quarterly 19 (1):107-23. https://doi.org/10.2307/249713.

Igbaria, Magid, Nancy Zinatelli, Paul Cragg, and Angele L. M. Cavaye. 1997. "Personal Computing Acceptance Factors in Small Firms: A Structural 
Equation Model.” MIS Quarterly 21 (3):279-305. https://doi.org/10.2307/249498.

Iivari, Juhani. 2005. "An Empirical Test of the DeLone-McLean Model of Information System Success.” ACM SIGMIS Database 36 (June):8-27. https://doi.org/10.1145/1066149.1066152.

Jain, Vikas, and Shivraj Kanungo. 2005. "Beyond Perceptions and Usage: Impact of Nature of Information Systems Use on Information System-Enabled Productivity." International Journal of Human-Computer Interaction 19 (1): 113 .

Kayhan, Varol Onur. 2015. "The Nature, Dimensionality, and Effects of Perceptions of Community Governance.” Information \& Management 52 (1):18-29. https://doi.org/10.1016/j.im.2014.10.004.

Kiew, Min-Yen, and Peter Seddon. 1994. "A Partial Test and Development of the DeLone and McLean Model of IS Success.” ICIS 1994 Proceedings 4 (1):99110.

Kositanurit, Boontaree, Ojelanki Ngwenyama, and Kweku-Muata Osei-Bryson. 2006. "An Exploration of Factors That Impact Individual Performance in an ERP Environment: An Analysis Using Multiple Analytical Techniques." European Journal of Information Systems 15 (6):556-568. https://doi.org/10.1057/palgrave.ejis.3000654.

Lee, Yang, Diane M. Strong, Beverly K. Kahn, and Richard Y. Wang. 2002. "AIMQ: A Methodology of Information Quality Assessment." Information and Management 40 (2):133-46.

Mader, Stewart. 2008. Wikipatterns. Indianapolis: Wiley Publishing.

Matschke, Christina, Johannes Moskaliuk, and Joachim Kimmerle. 2013. "The Impact of Group Membership on Collaborative Learning with Wikis." Cyberpsychology, Behavior and Social Networking 16 (2):127-31. https://doi.org/10.1089/cyber.2012.0254.

McKinney, Vicki, Kanghyun Yoon, and Fatemeh Mariam Zahedi. 2002. "The Measurement of Web-Customer Satisfaction: An Expectation and Disconfirmation Approach." Information Systems Research 13 (September):296-315.

Milovanović, Miloš, Miroslav Minović, Velimir Štavljanin, Marko Savković, and Dušan Starčević. 2012. "Wiki as a Corporate Learning Tool: Case Study for Software Development Company." Behaviour \& Information Technology 31 (8):767-77. https://doi.org/10.1080/0144929X.2011.642894.

Morgan, Jonathan T., Michael Gilbert, David W. McDonald, and Mark Zachry. 2013. "Project Talk: Coordination Work and Group Membership in WikiProjects." In Proceedings of the 9th International Symposium on Open Collaboration, 3:13:10. WikiSym '13. New York, NY, USA: ACM. https://doi.org/10.1145/2491055.2491058.

Negash, Solomon, Terry Ryan, and Magid Igbaria. 2003. "Quality and Effectiveness in Web-Based Customer Support Systems." Information \& Management 40 (8):757-68. https://doi.org/10.1016/S0378-7206(02)00101-5.

Nelson, R. Ryan, Peter A. Todd, and Barbara H. Wixom. 2005. "Antecedents of Information and System Quality: An Empirical Examination within the Context 
of Data Warehousing." Journal of Management Information Systems 21

(4):199-235.

Ortega, Felipe, and Gonzalez Barahona. 2007. "Quantitative Analysis of the Wikipedia Community of Users." In Proceedings of the 2007 International Symposium on Wikis. Montréal, Québec, Canada.

Ou, Carol X. J., Robert M. Davison, and Louie H. M. Wong. 2016. "Using Interactive Systems for Knowledge Sharing: The Impact of Individual Contextual Preferences in China." Information \& Management 53 (2):145-56. https://doi.org/10.1016/j.im.2015.09.007.

Palmer, Jonathan W. 2002. "Web Site Usability, Design, and Performance Metrics." Information Systems Research 13 (June):151-167. https://doi.org/10.1287/isre.13.2.151.88.

Parmaxi, Antigoni, and Panayiotis Zaphiris. 2015. "Specifying the Dynamics of Social Technologies as Social Microworlds." Behaviour \& Information Technology 34 (4):413-24. https://doi.org/10.1080/0144929X.2015.1004650.

Pentland, B. T. 1989. "Use and Productivity in Personal Computing." Proceedings of the Tenth International Conference on Information Systems, 211-222.

Petter, Stacie, William DeLone, and Ephraim McLean. 2008. "Measuring Information Systems Success: Models, Dimensions, Measures, and Interrelationships." European Journal of Information Systems 17 (3):236-63.

Philip, Raeth, Stefan Smolni, Nils Urbach, and Christian Zimmer. 2009. "Towards Assessing the Success of Social Software in Corporate Environments." AMCIS 2009 Proceedings, January, 662.

Po-An Hsieh, J J, and Wei Wang. 2007. "Explaining Employees Extended Use of Complex Information Systems." European Journal of Information Systems 16 (July):216-27. https://doi.org/10.1057/palgrave.ejis.3000663.

Podsakoff, Philip M, Scott B MacKenzie, Jeong-Yeon Lee, and Nathan P Podsakoff. 2003. "Common Method Biases in Behavioral Research: A Critical Review of the Literature and Recommended Remedies." The Journal of Applied Psychology 88 (5):879-903. https://doi.org/10.1037/0021-9010.88.5.879.

Poole, Erika Shehan, and Jonathan Grudin. 2010. "A Taxonomy of Wiki Genres in Enterprise Settings." In Proceedings of the 6th International Symposium on Wikis and Open Collaboration, 14:1-14:4. WikiSym '10. New York, NY, USA: ACM. https://doi.org/10.1145/1832772.1832792.

Prokofieva, Maria. 2013. "Evaluating Types of Students' Interactions in a Wiki-Based Collaborative Learning Project." Australasian Journal of Educational Technology 29 (4):496-512.

Rai, Arun, Sandra S. Lang, and Robert B. Welker. 2002. "Assessing the Validity of IS Success Models: An Empirical Test and Theoretical Analysis.” Information Systems Research 13 (1):50-69.

Razmerita, L, and K Kirchner. 2011. "How Wikis Can Be Used to Manage Knowledge in SMEs: A Case Study." Business Inform 28 (3):175-78.

Reid, Mike, Erik Jan Hultink, Tucker Marion, and Gloria Barczak. 2016. "The Impact of the Frequency of Usage of IT Artifacts on Predevelopment Performance in the NPD Process." Information \& Management 53 (4):422-34. https://doi.org/10.1016/j.im.2015.10.008. 
Reinhart, Gonzalez Jennifer. 2005. "Wiki and the Wiki Way: Beyond a Knowledge Management Solution." Information Systems Research Center, 1-22.

Rosemann, Micheal, and Iris Vessey. 2008. "Toward Improving the Relevance of Information Systems Research to Practice: The Role of Applicability Checks." Management Information Systems Quarterly 32 (1).

Saunders, Carol Stoak, and Jack William Jones. 1992. "Measuring Performance of the Information Systems Function." J. Manage. Inf. Syst. 8 (4):63-82.

Seddon, Peter B. 1997. "A Re-Specification and Extension of the DeLone and McLean Model of IS Success.” Information Systems Research 8 (3):240-53.

Sedera, Darshana, Guy Gable, and Taizan Chan. 2004. "A Factor and Structural Equation Analysis of the Enterprise Systems Success Measurement Model." In $A M C I S$. New York, N.Y., USA.

Shang, Shari S. C., Ya-Ling Wu, and Eldon Y. Li. 2016. "Field Effects of Social Media Platforms on Information-Sharing Continuance: Do Reach and Richness Matter?" Information \& Management. https://doi.org/10.1016/j.im.2016.06.008.

Stefanovic, Darko, Ugljesa Marjanovic, Milan Delić, Dubravko Culibrk, and Bojan Lalic. 2016. "Assessing the Success of E-Government Systems: An Employee Perspective." Information \& Management 53 (6):717-26. https://doi.org/10.1016/j.im.2016.02.007.

Tapscott, Don, and Anthony Williams. 2006. Wikinomics: How Mass Collaboration Changes Everything. Portfolio Hardcover.

Torkzadeh, G., and W. J. Doll. 1999. "The Development of a Tool for Measuring the Perceived Impact of Information Technology on Work.” Omega 27 (3):327-39.

Trkman, Marina, and Peter Trkman. 2009. “A Wiki as Intranet: A Critical Analysis Using the Delone and McLean Model." Online Information Review 33 (6):1087-1102.

Urbach, Nils, Stefan Smolnik, and Gerold Riempp. 2010. "An Empirical Investigation of Employee Portal Success." The Journal of Strategic Information Systems 19 (September):184-206.

Vreede, Gert-Jan de, Pedro Antunes, Julita Vassileva, Marco Aurélio Gerosa, and Kewen Wu. 2016. "Collaboration Technology in Teams and Organizations: Introduction to the Special Issue." Information Systems Frontiers 18 (1):1-6. https://doi.org/10.1007/s10796-016-9632-3.

Wagner, Christian, and Andreas Schroeder. 2010. "Capabilities and Roles of Enterprise Wikis in Organizational Communication.” Technical Communication 57 (1):68-89.

Waldrop, Mitch. 2008. “Big Data: Wikiomics.” Nature 455 (7209):22-25. https://doi.org/10.1038/455022a.

Wu, Jen-Her, and Yu-Min Wang. 2006. "Measuring KMS Success: A ReSpecification of the DeLone and McLean's Model." Information \& Management 43 (6):728-39.

Xiao, WengPeng, Chang Yan Chi, and Min Yang. 2007. "On-Line Collaborative Software Development via Wiki.” In , 177-83. Montréal, Québec, Canada.

Yuthas, Kristi, and Scott T. Young. 1998. "Material Matters: Assessing the Effectiveness of Materials Management IS." Information \& Management 33 (3):115-24. 


\section{Appendix I \\ Questionnaire Items}

\section{Collaboration quality}

Collaboration quality $(C Q)$

CQ1: The wiki enables an easy and comfortable communication with my colleagues.

CQ2: The wiki supports an effective and efficient sharing of information between the members of a project.

CQ3: The wiki enables a comfortable storing and sharing of documents with my colleagues.

CQ4: The wiki supports an effective networking between the members of a project in my organization.

CQ5: The wiki enables me to create and update documents collaboratively with my colleagues.

CQ6: Generally, the quality of collaboration of wiki system is good.

\section{Information quality}

Timeliness (TIME)

TIME1: The information provided by wiki is sufficiently current for my work.

TIME2: The information provided by wiki is sufficiently timely.

TIME3: The information provided by wiki is sufficiently up-to-date.

Relevance (RELEV)

RELEV1: The information provided by wiki is applicable to my tasks at work.

RELEV2: The information provided by wiki is related to my tasks at work.

RELEV3: The information provided by wiki is pertinent to my work.

RELEV4: In general, the wiki provides information relevant to my work.

Usefulness (USE)

USE1: The information provided by wiki is informative for my professional activities.

USE2: The information provided by wiki is valuable for the accomplishment of my tasks, and my project.

USE3: In general, the information from wiki is useful in my work.

Accuracy $(A C Y)$

ACY1: The information provided by wiki is accurate.

ACY2: The information provided by wiki is reliable.

ACY3: Generally, the information communicated by the wiki is correct and reliable.

Format (FORM)

FORM1: The information provided by wiki is clear in meaning.

FORM2: The information provided by wiki is easy to comprehend.

FORM3: The information provided by wiki is easy to read.

FORM4: In general, the information is understandable for me in making decisions.

System quality

Accessibility (ACC)

ACC1: The wiki system is responsive to my requests.

ACC2: The wiki system quickly loads the information pages.

ACC3: In general, the wiki provides good access to the information.

Ease of use (EOU)

EOU1: The wiki system has a simple layout for its contents.

EOU2: The wiki system is easy to use.

EOU3: The wiki system is well organized in terms of its operation.

EOU4: The wiki system has a clear design.

EOU5: In general, the wiki is user-friendly.

Reliability (RELIAB)

RELIAB1: The wiki system operates reliably. 
RELIAB2: The wiki system is technically free of errors (bugs).

RELIAB3: The operation of the wiki is dependable.

Interactivity (INTERACT)

INTERACT1: The wiki system provides the capability to create content /information.

INTERACT2: The wiki system provides the capability to edit information from an already created content.

INTERACT3: The wiki system enables me to customize information according to my needs. INTERACT4: In general, the wiki enables an active participation.

\section{Wiki use}

Active use (AU)

AU1: I regularly use wiki to share information in my job.

AU2: Wiki considerably improves the possibilities of sharing of my data and information.

AU3: In general, the frequency of use of wiki to share knowledge in the exercise of my profession is (rated on 'very low' to 'very high').

Passive use (PU)

PU1: I often use wiki to retrieve and collect information on the projects for which I work.

PU2: The wiki substantially decreases the time required for the acquisition of data and information relevant to my work.

PU3: Overall, the frequency of using wiki to retrieve knowledge for my work is (rated on 'very low' to 'very high').

\section{Wiki user satisfaction}

Collaboration satisfaction (COLLSAT)

Please indicate your level of satisfaction with the collaboration provided by wiki based on your experience.

COLLSAT1: Dissatisfied Vs. Satisfied ( 1 = Highly Dissatisfied, 5 = Highly Satisfied).

COLLSAT2: Displeased Vs. Pleased $(1=$ Very Displeased, $5=$ Very Pleased $)$.

COLLSAT3: Frustrated Vs. Contented $(1=$ Frustrated, $5=$ Contented).

COLLSAT4: Disappointed Vs. Delighted (1= Disappointed, 5= Delighted).

Information satisfaction (INFOSAT)

Based on the information quality provided by wiki, please indicate your views about the overall information quality.

INFOSAT1: Dissatisfied Vs. Satisfied (1 = Highly Dissatisfied, 5 = Highly Satisfied).

INFOSAT2: Displeased Vs. Pleased $(1=$ Very Displeased, $5=$ Very Pleased $)$.

INFOSAT3: Frustrated Vs. Contented ( $1=$ Frustrated, 5= Contented).

INFOSAT4: Disappointed Vs. Delighted (1= Disappointed, 5= Delighted).

System satisfaction (SYSSAT)

Based on your experience on the interaction with wiki, please indicate your views about the overall quality of wiki system.

SYSSAT1: Dissatisfied Vs. Satisfied (1 = Highly Dissatisfied, 5 = Highly Satisfied).

SYSSAT2: Displeased Vs. Pleased $(1=$ Very Displeased, $5=$ Very Pleased $)$.

SYSSAT3: Frustrated Vs. Contented (1= Frustrated, 5= Contented).

SYSSAT4: Disappointed Vs. Delighted (1= Disappointed, 5= Delighted).

\section{Perceived Individual performance}

\section{Efficiency $($ EFF $)$}

EFF1: The use of wiki system improves the rapidity of execution of my tasks.

EFF2: The use of wiki system facilitates the realization of my professional mission and achievement of my goals.

EFF3: The use of wiki system improves my personal productivity.

EFF4: Globally, I can be more profitable for my organization by using wikis.

Effectiveness (EFT) 
EFT1: The use of wiki system improves my professional competencies enabling me to develop knowledge necessary for my job.

EFT2: The use of wiki system makes me more independent by emphasizing my role within the enterprise.

EFT3: The use of wiki system helps me to achieve my goals by organizing my work.

EFT4: The use of wiki technology improves the quality of my work.

Capacity development (CAP)

CAP1: The use of wiki system improves my knowledge of enterprise activities.

CAP2: The use of wiki system me to exchange information on business with other functional units.

CAP3: The use of wiki system allows me to communicate within the enterprise and with the partners.

CAP4: The use of wiki system helps me, in general, to see and to deal with problems in a different manner. 


\section{Appendix II}

\section{Reliability, Convergent and Discriminant Validity}

\begin{tabular}{|c|c|c|c|c|c|c|c|}
\hline Construct & Item/Indicator & EFA/ CFA Factor loadings & $\alpha$ & CR & AVE & MSV & ASV \\
\hline Collaboration quality & CQ1 & $.801 / .786$ & .749 & .72 & .56 & .50 & .36 \\
\hline \multirow[t]{5}{*}{ Collaboration quality (CQ) } & $\mathrm{CQ} 2$ & $.612 / .600$ & & & & & \\
\hline & CQ3 & Item dropped & & & & & \\
\hline & CQ4 & $.847 / .613$ & & & & & \\
\hline & CQ5 & Item dropped & & & & & \\
\hline & CQ6 & $0.721 / .600$ & & & & & \\
\hline \multicolumn{8}{|l|}{ Information quality } \\
\hline \multirow[t]{3}{*}{ Timeliness (TIME) } & TIME1 & $0.877 / .824$ & .870 & .88 & .70 & .39 & .26 \\
\hline & TIME2 & $0.912 / .900$ & & & & & \\
\hline & TIME3 & 0.887 .790 & & & & & \\
\hline Relevance / Usefulness & RELEV1 & $0.851 / .794$ & .917 & .92 & .62 & .49 & .32 \\
\hline \multirow[t]{6}{*}{ (RELEV_USE) } & RELEV2 & $0.841 / .820$ & & & & & \\
\hline & RELEV3 & $0.861 / .845$ & & & & & \\
\hline & RELEV4 & $0.858 / .835$ & & & & & \\
\hline & USE1 & 0.747 .694 & & & & & \\
\hline & USE2 & $0.799 / .751$ & & & & & \\
\hline & USE3 & $0.797 / .747$ & & & & & \\
\hline \multirow[t]{3}{*}{ Accuracy (ACY) } & ACY1 & $0.914 / .867$ & .906 & .91 & .76 & .33 & .20 \\
\hline & $\mathrm{ACY} 2$ & $0.929 / .899$ & & & & & \\
\hline & ACY3 & $0.909 / .856$ & & & & & \\
\hline \multirow[t]{4}{*}{ Format (FORM) } & FORM1 & $0.862 / .834$ & .888 & .89 & .68 & .48 & .25 \\
\hline & FORM2 & $0.931 / .919$ & & & & & \\
\hline & FORM3 & $0.861 / .789$ & & & & & \\
\hline & FORM4 & $0.809 / .751$ & & & & & \\
\hline \multicolumn{8}{|l|}{ System quality } \\
\hline Accessibility / Ease of use & $\mathrm{ACC} 1$ & $0.732 / .671$ & .909 & .91 & .60 & .58 & .31 \\
\hline \multirow[t]{7}{*}{$\left(\mathrm{ACC} \_\mathrm{EOU}\right)$} & $\mathrm{ACC} 2$ & Item dropped & & & & & \\
\hline & $\mathrm{ACC} 3$ & $0.717 / .671$ & & & & & \\
\hline & EOU1 & 0.831 .786 & & & & & \\
\hline & EOU2 & $0.810 / .782$ & & & & & \\
\hline & EOU3 & $0.862 / .850$ & & & & & \\
\hline & EOU4 & $0.827 / .804$ & & & & & \\
\hline & EOU5 & $0.862 / .835$ & & & & & \\
\hline \multirow[t]{3}{*}{ Reliability (RELIAB) } & RELIAB 1 & $0.830 / .785$ & .871 & .88 & .71 & .40 & .17 \\
\hline & RELIAB2 & $0.928 / .817$ & & & & & \\
\hline & RELIAB3 & $0.918 / .925$ & & & & & \\
\hline \multirow[t]{4}{*}{ Interactivity (INTERACT) } & INTERACT1 & $0.865 / .909$ & .882 & .89 & .67 & .43 & .25 \\
\hline & INTERACT2 & $0.868 / .914$ & & & & & \\
\hline & INTERACT3 & $0.871 / .693$ & & & & & \\
\hline & INTERACT4 & $0.848 / .741$ & & & & & \\
\hline \multicolumn{8}{|l|}{ Wiki use } \\
\hline Active use / Passive use & AU1 & $0.861 / .824$ & .901 & .90 & .61 & .64 & .32 \\
\hline \multirow[t]{5}{*}{ (AU_PU) } & AU2 & $0.769 / .761$ & & & & & \\
\hline & AU3 & $0.845 / .776$ & & & & & \\
\hline & PU1 & $0.825 / .797$ & & & & & \\
\hline & PU2 & $0.705 / .692$ & & & & & \\
\hline & PU3 & $0.890 / .840$ & & & & & \\
\hline \multicolumn{8}{|l|}{ Wiki user satisfaction } \\
\hline Collaboration satisfaction / & COLLSAT1 & $0.857 / .826$ & .954 & .95 & .72 & .64 & .39 \\
\hline Information satisfaction & COLLSAT2 & $0.873 / .848$ & & & & & \\
\hline \multirow[t]{6}{*}{ (COLLSAT_INFOSAT) } & COLLSAT3 & $0.856 / .828$ & & & & & \\
\hline & COLLSAT4 & $0.873 / .851$ & & & & & \\
\hline & INFOSAT1 & $0.834 / .814$ & & & & & \\
\hline & INFOSAT2 & $0.887 / .875$ & & & & & \\
\hline & INFOSAT3 & $0.867 / .852$ & & & & & \\
\hline & INFOSAT4 & $0.891 / .882$ & .957 & .96 & .85 & .64 & .35 \\
\hline \multirow[t]{4}{*}{ System satisfaction (SYSSAT) } & SYSSAT1 & $0.937 / .926$ & & & & & \\
\hline & SYSSAT2 & $0.950 / .936$ & & & & & \\
\hline & SYSSAT3 & $0.934 / .899$ & & & & & \\
\hline & SYSSAT4 & $0.949 / .931$ & & & & & \\
\hline
\end{tabular}

Perceived individual performance 


\begin{tabular}{|c|c|c|c|c|c|c|c|}
\hline Efficiency / Effectiveness & EFF1 & $0.796 / .741$ & .881 & .90 & .57 & .50 & .50 \\
\hline \multirow{7}{*}{ (EFF_EFT) } & EFF2 & $0.769 / .717$ & & & & & \\
\hline & EFF3 & $0.860 / .829$ & & & & & \\
\hline & EFF4 & 0.778/.712 & & & & & \\
\hline & EFT1 & Item dropped & & & & & \\
\hline & EFT2 & $0.791 / .759$ & & & & & \\
\hline & EFT3 & $0.757 / .734$ & & & & & \\
\hline & EFT4 & $0.841 / .833$ & & & & & \\
\hline \multirow[t]{4}{*}{ Capacity development (CAP) } & CAP1 & $0.842 / .785$ & .905 & .88 & .65 & .50 & .25 \\
\hline & CAP2 & $0.860 / .811$ & & & & & \\
\hline & CAP3 & $0.864 / .803$ & & & & & \\
\hline & CAP4 & $0.869 / .826$ & & & & & \\
\hline
\end{tabular}

Note. $\alpha$, Cronbach's Alpha; CR, composite reliability; AVE, average variance extracted; MSV, maximum shared variance, ASV, average shared variance 